\title{
Bilateral reversed palmaris longus muscle: a case report and systematic literature review
}

\author{
Georga Longhurst ${ }^{1} \cdot$ Danya Stone ${ }^{2} \cdot$ Nick Mahony $^{3}$
}

Received: 7 August 2019 / Accepted: 17 October 2019 / Published online: 12 November 2019

(c) The Author(s) 2019

\begin{abstract}
Purpose We present a case of a bilateral reversed palmaris longus muscle and a systematic review of the literature on this anatomical variation.

Methods Routine dissection of a 90-year-old male cadaver revealed a rare bilateral reversed palmaris longus. This was documented photographically, and length and relation to anatomical landmarks were recorded. This finding stimulated a systematic review of the literature on the reversed palmaris longus variation, from which measurements were collated and statistical analysis performed to determine the prevalence, average length, relationship to side and sex, and to discuss its clinical and evolutionary implications.

Results The average length of the muscle belly and tendon of reversed palmaris longus was $135 \mathrm{~mm}$ and $126 \mathrm{~mm}$, respectively. Statistical analysis revealed no disparity in presentation due to sex and side; however, bilateral reversed palmaris longus has only been reported in males. A high proportion (70.8\%) of reversed palmaris longus were discovered in the right upper limb compared to the left.

Conclusion Variations in palmaris longus are purported to be as a result of phylogenetic regression. Clinically, patients with this variant may present with pain or swelling of the distal forearm, often as a result of intense physical exertion related to occupation or sport. Clinicians should be aware of this muscle variant as its presence could lead to confusion during tendon allograft harvesting procedures in reconstructive and tendon grafting surgery.
\end{abstract}

Keywords Palmaris longus $\cdot$ Reversed $\cdot$ Reverse $\cdot$ Inverted $\cdot$ Bilateral $\cdot$ Anatomical variation $\cdot$ Muscle

\section{Introduction}

Palmaris longus (PL) is a muscle of the anterior compartment of the forearm. It is located within the superficial group of flexor muscles, medial and superficial to pronator teres and flexor carpi radialis, and lateral to flexor carpi ulnaris.

Georga Longhurst

glonghur@sgul.ac.uk

Danya Stone

d.stone@bsms.ac.uk

Nick Mahony

njmahony@tcd.ie

1 Anatomical Sciences, St George's, University of London, London, UK

2 Department of Anatomy, Brighton and Sussex Medical School, Brighton, UK

3 Department of Anatomy, Trinity College, University of Dublin, Dublin, Ireland
It is attached to the medial epicondyle and epicondylar ridge of the humerus via the common flexor tendon. Typically, the fusiform muscle belly runs distally and becomes tendinous in the mid-forearm. Tendinous fibers insert into the flexor retinaculum and palmar aponeurosis of the hand. Due to its insertion points, PL acts as an accessory flexor muscle and as an anchor of the skin and fascia to resist horizontal shearing forces. The neurovascular supply to PL is through the median nerve and branches of the ulnar artery [43].

Palmaris longus is considered to be the most variable muscle in human anatomy. The most common variation is complete agenesis, which is prevalent in $20.25 \%$ of the global population [49]. When present, PL can be digastric, duplicated, bifurcated, trifurcated or have atypical tendinous insertions [16]. While variations of PL are common, it is essential that rare presentations of the muscle are reported on, as these variations have important surgical and clinical implication. Firstly, PL is often used for tendon grafting and reconstructive surgeries as the removal of 
the muscle does not affect the function of the forearm and it is easily resected due to its superficial location [36]. The presence of a reversed PL (RPL) may prevent the tendon from being harvested for tendon grafting. Secondly, if present, RPL may be a rare cause of symptoms of neuropathy and neural compression, due to its close anatomical relationship to the median and ulnar nerves $[15,16]$.

\section{Materials and methods}

\section{Case report}

A 90-year-old male cadaver was fixed traditionally with $10 \%$ formalin. Skin and subcutaneous tissue of the forearms were reflected, and the antebrachial fascia and bicipital aponeuroses were removed. PL was observed to be in a reversed orientation bilaterally. RPL was separated from its fascial compartments and measurements of the tendons and muscle bellies were recorded with a $150 \mathrm{~mm}$ range digital-pocket-caliper (Scala, Germany). The proximal tendon was measured from the medial epicondyle of the humerus to the most proximal visible muscle fiber. The muscle bellies were measured from the most proximal to the most distal visible muscle fiber. The distal tendons were measured from the most distal muscle fiber to the tendon's insertion point onto the palmar aponeurosis at a line between the proximal scaphoid and pisiform bones. Each measurement was duplicated and an average (mean) length was calculated.

\section{Literature review}

A literature review was conducted using PubMed and Google Scholar databases, using the keywords: 'reserved palmaris longus' or 'reverse palmaris longus'. Only papers which reported the presence of RPL were discussed. All related articles were carefully reviewed and studies that did not include information on side and sex were excluded from the study. The prevalence of RPL in surgical and cadaveric cases and the average length of the tendon and muscle belly was calculated. A Chi squared test with Fisher's exact post hoc test was performed with GraphPad Prism (Version 6e) to assess the relationship of RPL to sex and side.

Primary consent was given by all donors in line with best practice guidelines developed by the Anatomical Committee of the Irish Medical Schools and the Medical Council of Ireland.

Research ethics committee approval for this study from the School of Medicine Research Ethics Committee at Trinity College Dublin was also obtained.

\section{Results}

\section{Case report}

Palmaris longus was reversed bilaterally with a proximal tendon, originating from the medial epicondyle of the humerus and distal muscle belly, inserting via a short distal tendon onto the flexor retinaculum and palmar aponeurosis of the hand. All other anatomical relations were consistent with the literature; however, the left RPL received an additional slip of muscle from flexor digitorum superficialis near its proximal insertion. Both arms showed no signs of muscular atrophy or hypertrophy. Proximally, the median nerve travelled deep to PL and there was no indication of median nerve entrapment along its course. Distally, the median nerve travelled more superficially in the carpal tunnel and entered the wrist lateral to RPL (Fig. 1).

The total lengths of the two (bilateral) RPL were $264 \mathrm{~mm}$ and $246 \mathrm{~mm}$ on the right and left forearms, respectively. The proximal and distal tendons were longer on the right side at $119 \mathrm{~mm}$ and $50 \mathrm{~mm}$, respectively, compared to $116 \mathrm{~mm}$ and $11 \mathrm{~mm}$ on the left. Conversely, the muscle belly on the left was longer on the left side at $120 \mathrm{~mm}$ compared to $96 \mathrm{~mm}$ on the right (Table 1).

\section{Literature review}

A total of 152 relevant articles were accessed from the years 1814 to 2019. Fifty-five cases of RPL were recorded in 39 of these articles (Table 2). Six articles were excluded after initial screening as they did not contain information on sex or side. In total, 33 articles were included that report. Thirteen (39.4\%) variants were revealed through cadaveric studies, while $20(60.4 \%)$ were reported in clinical case studies as a result of pain and swelling in the distal anterior forearm, and subsequent surgical intervention, or through ultrasound or magnetic resonance imaging (MRI).

Taking our measurements, and the six reported in the literature into consideration, the average recorded length of the muscle belly and proximal tendon of RPL was $135 \mathrm{~mm}$ and $126 \mathrm{~mm}$, respectively (Table 3). Of the 43 individuals where information on sex was available, $20(46.5 \%)$ were female and $23(53.5 \%)$ were male. Of the 48 upper limbs where information on side was available, 34 (70.9\%) RPL presented in the right forearm, while 14 (29.1\%) were found in the left. When isolating results from cadaveric studies, of 15 cases $7(46.7 \%)$ were found in the right upper limb and 8 $(53.3 \%)$ in the left. Five males $(100 \%)$ presented with bilateral RPL. A Chi squared test with Fisher's post hoc revealed no statistical difference in the frequency of presentation of RPL $(P>0.05)$ due to sex and side. 
Fig. 1 Dissection of right (a) and (b) left anterior compartment of the forearm demonstrating bilaterally reversed palmaris longus. $P L$ palmaris longus, $P T P L$ proximal tendon palmaris longus, $D T P L$ distal tendon palmaris longus, $A d P L$ additional slip of palmaris longus, FDS flexor digitorum superficialis, $F C R$ flerox carpi radialis, $B R$ brachioradialis, $P T$ pronator teres, $R A$ radial artery

Table 1 Measurements of reversed palmaris longus muscle from case study

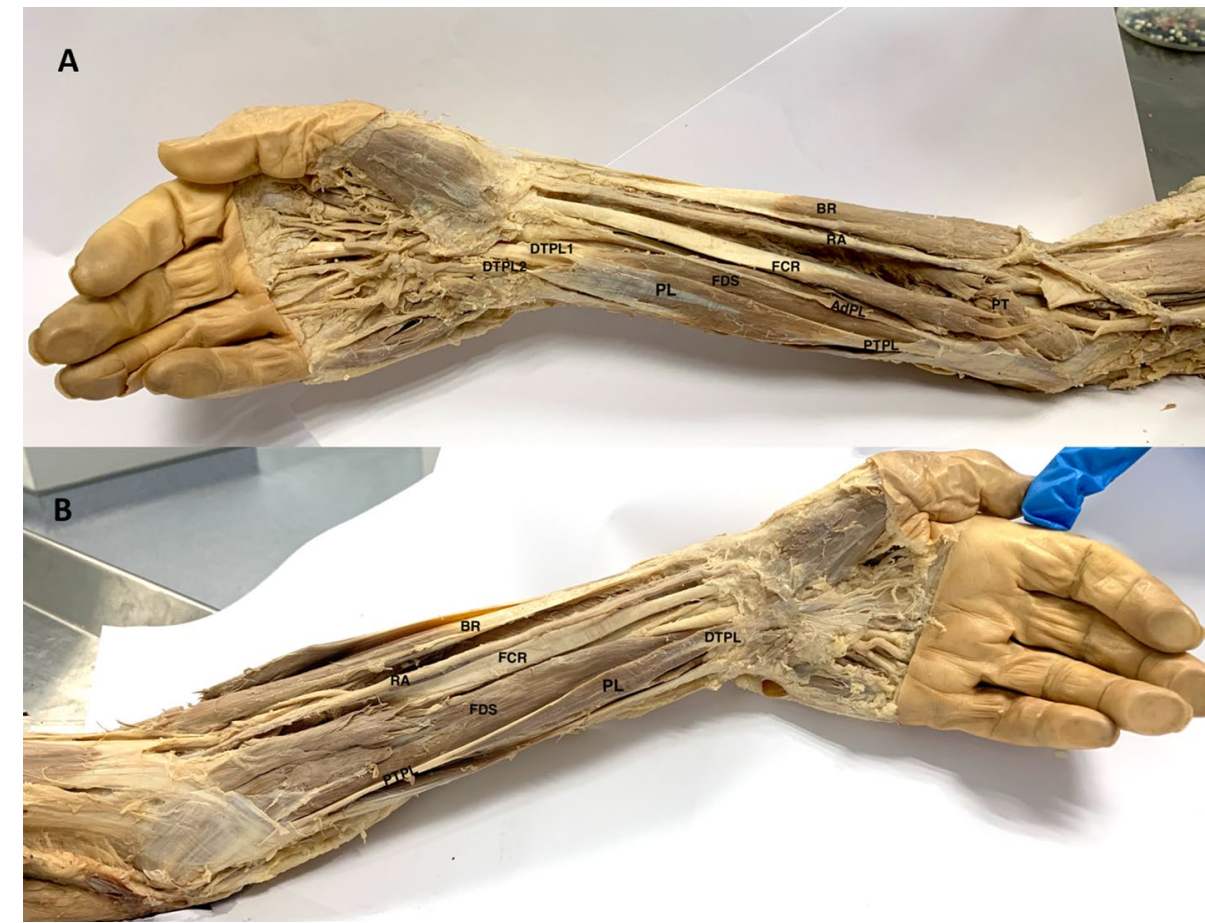

\begin{tabular}{|c|c|c|c|c|c|c|c|}
\hline \multicolumn{4}{|c|}{ Right (mm) } & \multicolumn{4}{|c|}{ Left $(\mathrm{mm})$} \\
\hline DT & $\mathrm{MB}$ & $\mathrm{PT}$ & Total & DT & MB & $\mathrm{PT}$ & Total \\
\hline 50 & 96 & 119 & 264 & 11 & 120 & 116 & 246 \\
\hline
\end{tabular}

$D T$ distal tendon, $M B$ muscle belly, $P T$ proximal tendon

\section{Discussion}

One of the earliest reports of RPL was discovered through dissection in 1868 at King's College London [48]. The earliest clinical presentation, from our literature review, of bilateral RPL was reported in Germany in 1993 in a 21-year-old male who had suffered from median nerve compression, outside the carpal tunnel, as a result of hypertrophy of the muscle. Resection of the muscle belly relieved the symptoms immediately [19]. Three cases of bilateral RPL were reported in male donors from Chile [39], Brazil [23] and India [21]. All reports of RPL originated from the medial epicondyle of the humerus; however, the distal insertion points varied. One case reported on a short distal tendon on the left side, similar to our findings, which inserted into the distal aponeurosis [39]. Conversely, the remaining RPL attached to their distal insertion points via the distal muscular bellies directly [23]. Another case reported on a trifid insertion, which was laterally continuous with the fascia of the thenar muscles, centrally continuous with the palmar aponeurosis, and medially continuous with the fascia covering abductor digiti minimi [21]. The reported cases of RPL also showed differences in their relationship with the median nerve in the wrist. The right muscle and tendon were situated lateral to the median nerve, whereas the distal third of the left muscle compressed the median nerve [39].

There was no obvious correlation between sex and RPL. However, it is interesting to note that reports of bilateral cases of RPL have only been discovered in male donors to date, despite widespread anatomical dissection throughout the world. Perhaps this occurrence of RPL serves as an example of a minor evolutionary dimorphism between the sexes. A hypothesis warrants further investigations. Collating results from literature revealed a higher frequency of RPL in right upper limb. However, when only taking cadaveric studies into consideration, there is no difference in sidedness. This suggests that results for sidedness may not reflect the frequency of RPL in the population, but rather be skewed due to presentation in clinical scenarios. As RPL in right and left hand mirrors the population proportions of left and right handedness, this suggests that clinical presentations of symptoms of RPL result from increased activity of dominant limbs. 
Table 2 Prevalence of reversed palmaris longus in the literature

\begin{tabular}{|c|c|c|c|c|c|}
\hline Study & No & Sex & Side & Loc & Clinical implications \\
\hline Tenaw, 2018 [45] & 1 & M & $\mathrm{R}$ & $\mathrm{CA}$ & \\
\hline Getzmann and Schweizer, 2018 [18] & 1 & $\mathrm{~F}$ & $\mathrm{R}$ & $\mathrm{CL}$ & Competitive swimmer; swelling and pain of distal forearm with activity \\
\hline George and Hassan, 2018 [15] & 1 & $\mathrm{~F}$ & $\mathrm{~L}$ & CL & Gymnast; swelling and pain of distal forearm \\
\hline Bhashyam et al., 2017 [5] & 1 & M & $\mathrm{L}$ & $\mathrm{CL}$ & Laborer; exercise exacerbated, pain of distal forearm, ulnar nerve paresthesia \\
\hline \multirow[t]{2}{*}{ Twoon et al., 2017 [47] } & 2 & $\mathrm{~F}$ & $\mathrm{~L}$ & CL & $\begin{array}{l}\text { Competitive weightlifter; pain and swelling of distal forearm, exercise exacerbated } \\
\text { symptoms }\end{array}$ \\
\hline & & M & $\mathrm{R}$ & $\mathrm{CL}$ & $\begin{array}{l}\text { Keen sportsman; pain and swelling distal forearm, initially exercise exacerbated } \\
\text { symptoms }\end{array}$ \\
\hline Pires et al., 2018 [37] & 1 & M & $\mathrm{R}$ & $\mathrm{CA}$ & \\
\hline Marpalli et al., 2016 [27] & 1 & M & $\mathrm{R}$ & $\mathrm{CA}$ & \\
\hline Mathew et al., 2015 [28] & 1 & M & $\mathrm{L}$ & $\mathrm{CA}$ & \\
\hline Eren et al., 2015 [9] & 1 & M & $\mathrm{R}$ & $\mathrm{CL}$ & Swelling of distal forearm \\
\hline Gune et al., 2014 [21] & 2 & M & $\mathrm{B}$ & $\mathrm{CA}$ & \\
\hline Heck and Campos, 2014 [23] & 2 & M & $\mathrm{B}$ & $\mathrm{CA}$ & \\
\hline Murabit et al., 2013 [31] & 1 & $\mathrm{~F}$ & $\mathrm{~L}$ & $\mathrm{CA}$ & \\
\hline Salgado et al., 2012 [39] & 2 & M & $\mathrm{B}$ & $\mathrm{CA}$ & \\
\hline Cope et al., 2009 [7] & 1 & $\mathrm{~F}$ & $\mathrm{R}$ & $\mathrm{CA}$ & Machine operator \\
\hline Georgiev and Jelev, 2009 [17] & 1 & $\mathrm{~F}$ & $\mathrm{~L}$ & $\mathrm{CA}$ & \\
\hline Acikel et al., 2007 [1] & 1 & M & $\mathrm{R}$ & $\mathrm{CL}$ & $\begin{array}{l}\text { Soldier; swelling of distal forearm, exercise exacerbated pain, symptoms of median } \\
\text { and ulnar nerve compression }\end{array}$ \\
\hline Fazan., 2007 [12] & 1 & $\mathrm{~F}$ & $\mathrm{~L}$ & $\mathrm{CA}$ & Median nerve compression \\
\hline Ogun et al., 2007 [34] & 1 & M & $\mathrm{R}$ & $\mathrm{CL}$ & Asymptomatic \\
\hline Natsis et al., 2007 [32] & 1 & $\mathrm{~F}$ & $\mathrm{~L}$ & $\mathrm{CA}$ & \\
\hline Seyhan, 2005 [42] & 1 & M & $\mathrm{R}$ & $\mathrm{CL}$ & Median nerve compression \\
\hline Bencteux et al. 2001 [4] & 1 & $\mathrm{~F}$ & $\mathrm{R}$ & $\mathrm{CL}$ & Pain and swelling of distal forearm \\
\hline Yildiz et al. 2000 [50] & 1 & $\mathrm{~F}$ & $\mathrm{R}$ & CL & Pain and swelling of distal forearm \\
\hline \multirow[t]{4}{*}{ Schuurman and van Gils, 2000 [41] } & 4 & M & $\mathrm{R}$ & $\mathrm{CL}$ & All patients with effort-related median nerve compression \\
\hline & & $\mathrm{F}$ & $\mathrm{R}$ & CL & \\
\hline & & $\mathrm{F}$ & $\mathrm{R}$ & $\mathrm{CL}$ & \\
\hline & & $\mathrm{F}$ & $\mathrm{R}$ & $\mathrm{CL}$ & Swelling of distal forearm \\
\hline \multirow[t]{2}{*}{ Depuydt et al., 1998 [8] } & 2 & $\mathrm{~F}$ & $\mathrm{R}$ & $\mathrm{CL}$ & \\
\hline & & $\mathrm{F}$ & $\mathrm{R}$ & CL & \\
\hline Ninkovic and Ohler, 1995 [33] & 1 & M & $\mathrm{R}$ & CL & Lumberjack; pain and swelling distal anterior forearm, median nerve paresthesia \\
\hline Giunta et al., 1993 [19] & 2 & M & $\mathrm{B}$ & $\mathrm{CL}$ & Bilateral, median nerve compression, symptoms while working \\
\hline Güler and Çeliköz, 1998 [20] & 1 & M & $\mathrm{R}$ & CL & Pain, numbness and tingling in thumb, index and middle finger \\
\hline Regan et al., 1988 [38] & 1 & M & $\mathrm{R}$ & CL & $\begin{array}{l}\text { Carpenter: Ulnar nerve compression with tingling of little finger. Blue swelling of } \\
\text { wrist }\end{array}$ \\
\hline Meyer and Pflaum, 1987 [29] & 1 & $\mathrm{~F}$ & $\mathrm{R}$ & CL & Paresthesia in median nerve distribution, swelling of distal forearm \\
\hline Schlafly and Lister, 1987 [40] & 1 & $\mathrm{~F}$ & $\mathrm{R}$ & $\mathrm{CL}$ & $\begin{array}{l}\text { Sales clerk; median nerve parenthesis with diffuse blue swelling. Weakness in } \\
\text { thenar movement }\end{array}$ \\
\hline \multirow[t]{3}{*}{ Fragiadakis et al., 1978 [13] } & 3 & M & $\mathrm{R}$ & $\mathrm{CL}$ & Median nerve compression \\
\hline & & M & $\mathrm{R}$ & CL & Asymptomatic \\
\hline & & $\mathrm{F}$ & $\mathrm{R}$ & CL & Asymptomatic \\
\hline \multirow[t]{3}{*}{ Still and Kleinert, 1973 [44] } & 3 & M & $\mathrm{R}$ & $\mathrm{CL}$ & $\begin{array}{l}\text { English professor; pain in volar aspect of right forearm that was accentuated by } \\
\text { exercise, Median nerve paresthesia }\end{array}$ \\
\hline & & $\mathrm{F}$ & $\mathrm{R}$ & $\mathrm{CL}$ & $\begin{array}{l}\text { Onset of pain when lifting heavy objects. Median nerve compression, thenar atro- } \\
\text { phy and decreased sensation in thumb, index and middle finger }\end{array}$ \\
\hline & & $\mathrm{F}$ & $\mathrm{R}$ & CL & Cashier; occasional numbness and tingling of entire hand. \\
\hline Morrison, 1916 [30] & 1 & M & $\mathrm{L}$ & $\mathrm{CA}$ & Asymptomatic \\
\hline
\end{tabular}

No number, $M$ male, $F$ female, $R$ right, $L$ left, $B$ bilateral, $L o c$ location, $C A$ cadaver, $C L$ clinical 
Table 3 Measurements of reversed palmaris longus from the literature

\begin{tabular}{lllll}
\hline Study & Side & Sex & MB (mm) & PT (mm) \\
\hline Gune et al., 2014 [21] & R & M & 150 & 115 \\
Gune et al., 2014 [21] & L & M & 130 & 135 \\
Heck and Campos, 2014 [23] & R & M & 210 & 150 \\
Heck and Campos, 2014 [23] & L & M & 150 & 110 \\
Georgiev and Jelev, 2009 [16] & L & F & 136 & 89 \\
Fazan, 2007 [12] & L & F & 88 & 177 \\
Case study & R & M & 96 & 119 \\
Case study & L & M & 120 & 116 \\
Mean & & & 135 & 126 \\
SD & & & 37.9 & 27.1 \\
\hline
\end{tabular}

$R$ right, $L$ left, $M B$ muscle belly, $P T$ proximal tendon

Previous studies have assessed the prevalence of bilateral agenesis of PL to sex and also reported no statistical correlation [26]. Conversely, a meta-analysis performed by Yammine et al. found that there is a statistically higher rate of agenesis on the right side compared to the left, but no significant difference between the combination of side and sex. In addition, the proportion of agenesis varies between different ethnic groups, with the lowest proportion among the East Asian and African population, and the highest observed in the Arab Middle Eastern population [49].

Only six sets of measurements of RPL muscle have been recorded in the literature from three previous studies $[16,20,22]$. As we report on a bilateral occurrence, we contribute two further measurements. Both tendon measurements were similar to those reported in the literature. The left tendon was $3 \mathrm{~mm}$ shorter than the average tendon measurement, whereas the right tendon did not deviate from the average (Table 2). Conversely, both muscle bellies were considerably shorter than the average measurement. The right muscle belly deviated $46 \mathrm{~mm}$ from the mean, while the left deviated $22 \mathrm{~mm}$ (Table 2).

Accurate measurements of PL are necessary as the muscle is often used in tendon grafting procedures to treat facial paralysis, ptosis correction and lip augmentation [36] and reconstructive surgeries [14]. According to Harvey and colleagues, a tendon must be greater than $150 \mathrm{~mm}$ for it to be suitable for tendon grafting [22]. We report that the average tendon length of RPL is $126 \mathrm{~mm}$ implying that this muscular anomaly is not suitable for tissue harvesting. Although it must be noted that a graft longer than $15 \mathrm{~cm}$ may not always be required depending on the type of reconstruction taking place [24]. Therefore, if possible ultrasound should be utilized to measure the tendon length and suitability for grafting pre-operatively. If ultrasound is not available, ineligibility of the muscle for use in tendon grafting may only be discovered intraoperatively $[24,25]$. This may result in negative consequences for both the patient and surgeon as morbidity may increase and the patient may not have given consent for the harvesting of alternative tissue [11].

When discovered in a clinical scenario, RPL is often present in athletes or in professions that require intense physical exertion, such as lumberjacks, soldiers and manual laborers $[14,17,48]$. The repeated action of axial loading, power gripping and flexion/extension stresses can cause the muscle belly of the RPL to hypertrophy. The additional volume and pressure in the flexor compartment of the forearm may cause exertional compartment syndrome resulting in median or ulnar nerve paranesthesia and effort-related volar forearm pain $[1,8,39]$. Clinicians, physiotherapists and radiologists should be aware of this rare muscular anomaly, as it may be overlooked when diagnosing forearm pain and could be mistaken for a tumor or ganglion on MRI or clinical examination [4, 17].

Anatomical variations in the PL muscle are a consequence of phylogenetic degeneration [43]. This occurred as a result of a shift from quadrupedal or arboreal locomotion to habitual bipedalism during human evolution. As the function of the forearm evolved from a weight-bearing forelimb to a prehensile limb, capable of precise movement, the flexor muscles have partially atrophied in a caudocranial direction [2]. In fact, the relative tendon size of PL increases from ancestral genera, such as lemuriformes and new world primates, to more derived genera such as great apes including modern humans [3]. This shortening of the muscular belly has resulted in an overall weakening of the muscle and, as a result, complete agenesis of the PL does not affect forearm function. The anatomical variations of PL and its rudimentary function have led to the hypothesis that the upper extremity in man is still undergoing a process of evolution $[6,10]$.

Variations of the PL muscle are caused by disturbances of the intracellular or extracellular pathways that control embryonic muscle growth, which cannot be compensated for during later development. Anomalies and agenesis of PL in human fetuses are similar to those observed in adults [35]. Interestingly, variations in PL are distinctly heritable. Thomson et al. hypothesized that partial or complete absence of the muscle is due to a single dominant gene, which acts as an inhibitor of its development, but this inhibition is frequently incomplete due to modifying conditions such as sex and side [46].

Although a search strategy was implemented, it cannot be assumed that all articles containing information on this variant were included. However, efforts were made to include the most relevant studies containing the most information relevant to this review. 


\section{Conclusion}

Variations in the PL muscle are not uncommon and are purported to be as a result of phylogenetic regression. We have presented a further rare bilateral anomaly of a RPL again in male cadaver. Clinicians should be aware of this muscle variant as it may be a rare cause of volar wrist pain in gripintensive sports or occupations and may give rise to confusion in reconstructive and plastic surgery.

Author contributions GL: project development, data collection and management, data analysis, manuscript writing and editing. DS: project development, data collection and management, manuscript writing. NM: manuscript editing.

\section{Compliance ethical standards}

Conflict of interest The authors declare that they have no conflict of interest.

Open Access This article is distributed under the terms of the Creative Commons Attribution 4.0 International License (http://creativeco mmons.org/licenses/by/4.0/), which permits unrestricted use, distribution, and reproduction in any medium, provided you give appropriate credit to the original author(s) and the source, provide a link to the Creative Commons license, and indicate if changes were made.

\section{References}

1. Acikel C, Ulkur E, Karagoz H, Celikoz B (2007) Effort-related compression of median and ulnar nerves as a result of reversed three-headed and hypertrophied palmaris longus muscle with extension of Guyon's canal. Scand J Plast Reconstr Surg Hand Surg 41:45-47

2. Ashby BS (1964) Hypertrophy of the palmaris longus muscle; report of a case. J Bone Jt Surg Br 46:230-232

3. Aversi-Ferreira RA, Bretas RV, Maior RS, Davaasuren M, Paraguassu-Chaves CA, Nishijo H, Aversi-Ferreira TA (2014) Morphometric and statistical analysis of the palmaris longus muscle in human and non-human primates. Biomed Res Int 2014:178906

4. Bencteux P, Simonet J, el Ayoubi L, Renard M, Attignon I, Dacher JN, Thiebot J (2001) Symptomatic palmaris longus muscle variation with MRI and surgical correlation: report of a single case. Surg Radiol Anat 23:273-275

5. Bhashyam AR, Harper CM, Iorio ML (2017) Reversed palmaris longus muscle causing volar forearm pain and ulnar nerve paresthesia. J Hand Surg 42:298.e291-298.e295

6. Capdarest-Arest N, Gonzalez JP, Turker T (2014) Hypotheses for ongoing evolution of muscles of the upper extremity. Med Hypotheses 82:452-456

7. Cope JM, Looney EM, Craig CA, Gawron R, Lampros R, Mahoney R (2009) Median nerve compression and the reversed palmaris longus. Int J Anat Var 2:102-104

8. Depuydt KH, Schuurman AH, Kon M (1998) Reversed palmaris longus muscle causing effort-related median nerve compression. J Hand Surg Br 23:117-119

9. Eren F, Melikoglu C, Kok D, Iskender S (2015) Reversed palmaris longus forming a mass in the distal forearm. Int $\mathrm{J}$ Anat Var 8:37-39
10. Eric M, Krivokuca D, Savovic S, Leksan I, Vucinic N (2010) Prevalence of the palmaris longus through clinical evaluation. Surg Radiol Anat 32:357-361

11. Erquicia JI, Gelber PE, Doreste JL, Pelfort X, Abat F, Monllau JC (2013) How to improve the prediction of quadrupled semitendinosus and gracilis autograft sizes with magnetic resonance imaging and ultrasonography. Am J Sports Med 41:1857-1863

12. Fazan VPS (2007) Reversed palmaris longus muscle and median nerve relationships: case report and literature review. Braz J Morphol Sci 24(2):88-91

13. Fragiadakis EG, Papavassiliou N, Giannikas A (1978) Variations of palmaris longus. Handchirurgie 10(149-151):14

14. Gandhi MJ, Knight TP, Ratcliffe PJ (2016) Scapholunate ligament reconstruction using the palmaris longus tendon and suture anchor fixation in chronic scapholunate instability. Indian J Orthop 50:616-621

15. George SC, Hassan Z (2018) A bifid reversed palmaris longus muscle causing median nerve compression in a child. J Hand Surg Eur 43:665-666

16. Georgiev GP, Iliev AA, Dimitrova IN, Kotov GN, Malinova LG, Landzhov BV (2017) Palmaris Longus muscle variations: clinical significance and proposal of new classifications. Folia Med 59:289-297

17. Georgiev GP, Jelev L (2009) Unusual coexistence of a variant abductor digiti minimi and reversed palmaris longus and their possible relation to median and ulnar nerves entrapment at the wrist. Rom J Morphol Embryol 50:725-727

18. Getzmann JM, Schweizer A (2018) Surgical resection of a reversed palmaris longus muscle causing chronic exertional compartment syndrome in a competitive swimmer: a case report. Orthop J Sports Med 6:2325967118769615

19. Giunta R, Brunner U, Wilhelm K (1993) Bilateral reversed palmaris longus muscle-a rare cause of peripheral median nerve compression syndrome. Case report. Unfallchirurg 96:538-540

20. Güler and Çeliköz (1998) Anomalous palmaris longus muscle causing carpal tunnel-like syndrome. Arch Orthop Trauma Surg 4:296-297

21. Gune AR, Pote AJ, Patil AD, Patil PS, Nikam VR (2014) Bilateral reversed palmaris longus muscle with trifid insertion, a rare variation. Int J Res Med Sci 2:741-743

22. Harvey FJ, Chu G, Harvey PM (1983) Surgical availability of the plantaris tendon. J Hand Surg Am 8:243-247

23. Heck L, Campos D (2014) Embryological considerations on the bilateral reversed palmaris longus muscle: a case report in human. J Morph Sci 31:58-61

24. Jakubietz MG, Jakubietz DF, Gruenert JG, Zahn R, Meffert RH, Jakubietz RG (2011) Adequacy of palmaris longus and plantaris tendons for tendon grafting. J Hand Surg Am 36:695-698

25. Johnson CC, Vutescu ES, Miller TT, Nwawka OK, Lee SK, Wolfe SW (2018) Ultrasound determination of presence, length and diameter of the palmaris longus tendon. J Hand Surg Eur 43:948-953

26. Kigera JWM, Mukwaya S (2011) Frequency of agenesis palmaris longus through clinical examination-an East African study. PLoS One 6:e28997

27. Marpalli S, Bhat ALS, Gadahad MRK (2016) A case of reverse palmaris longus muscle - an additional muscle in the anterior compartment of the forearm. J Clin Diagn Res 10:AD03-AD04

28. Mathew AJ, Sukumaran TT, Joseph S (2015) Versatile but temperamental: a morphological study of palmaris longus in the cadaver. J Clin Diagn Res 9:AC01-AC03

29. Meyer FN, Pflaum BC (1987) Median nerve compression at the wrist caused by a reversed palmaris longus muscle. J Hand Surg Am 12:369-371 
30. Morrison JT (1916) A palmaris longus muscle with a reversed belly, forming an accessory flexor muscle of the little finger. J Anat Physiol 50:324-326

31. Murabit A, Gnarra M, Mohamed A (2013) Reversed palmaris longus muscle: anatomical variant-case report and literature review. Can J Plast Surg 21:55-56

32. Natsis K, Levva S, Totlis T, Anastasopoulos N, Paraskevas G (2007) Three-headed reversed palmaris longus muscle and its clinical significance. Ann Anat 189:97-101

33. Ninkovic M, Ohler HK (1995) Acute median nerve compression produced by reversed palmaris longus muscle. Eur J Plast Surg 18:129-130

34. Ogun TC, Karalezli N, Ogun CO (2007) The concomitant presence of two anomalous muscles in the forearm. Hand (N Y) $2: 120-122$

35. Olewnik L, Wasniewska A, Polguj M, Podgorski M, Labetowicz P, Ruzik K, Topol M (2018) Morphological variability of the palmaris longus muscle in human fetuses. Surg Radiol Anat 40:1283-1291

36. Pal JN, Bera AK, Roy AN, Bari W (2016) Palmaris longus tendon grafting for extensor pollicis longus tendon rupture bScrew tip after 20 years. J Orthop Case Rep 6:25-27

37. Pires L, Perisse JP, Araujo GCS, Manaia J, Fonseca Junior A, Babinski MA (2018) Hypertrophic reversed palmaris longus muscle: a cadaveric finding. Folia Morphol 77:403-405

38. Regan PJ, Roberts JO, Bailey BN (1988) Ulnar nerve compression caused by a reversed palmaris longus muscle. J Hand Surg Br 13:406-407

39. Salgado G, Cantin M, Inzunza O, Munoz A, Saez J, Macuer M (2012) Bilateral reversed palmaris longus muscle: a rare anatomical variation. Folia Morphol 71:52-55
40. Schlafly B, Lister G (1987) Median nerve compression secondary to bifid reversed palmaris longus. J Hand Surg 12:371-373

41. Schuurman AH, van Gils AP (2000) Reversed palmaris longus muscle on MRI: report of four cases. Eur Radiol 10:1242-1244

42. Seyhan T (2005) Median nerve compression at the wrist caused by reversed 3-headed palmaris longus muscle: case report and review of the literature. Am J Orthop 34:544-546

43. Standring S (2015) Gray's anatomy: the anatomical basis of clinical practice, 41st edn. Elsevier Health Sciences, New York, p 850

44. Still J, Kleinert H (1973) Anomalous muscles and nerve entrapment in the wrist and hand. Plast Reconstr Surg 52:394-400

45. Tenaw B (2018) Unilateral reversed palmaris longus muscleanatomical variation: a case report. J Clin Case 1:1014

46. Thompson JW, McBatts Danforth (1921) Hereditary and racial variation in the musculus palmaris longus. Am J Phys Anthropol 4:205-218

47. Twoon M, Jones CD, Foley J, Davidson D (2017) Reversed palmaris longus muscle: a report of two cases. Case Rep Plast Surg Hand Surg 4:73-76

48. Wood J (1867) IV. Variations in human myology observed during the winter session of 1866-67 at King's college, London. Proc R Soc Lond 15:518-546

49. Yammine K (2013) Clinical prevalence of palmaris longus agenesis: a systematic review and meta-analysis. Clinc Anat 26:709-718

50. Yildiz M, Sener M, Aynaci O (2000) Three-headed reversed palmaris longus muscle: a case report and review of the literature. Surg Radiol Anat 22:217-219

Publisher's Note Springer Nature remains neutral with regard to jurisdictional claims in published maps and institutional affiliations. 